\title{
Monte Carlo simulations of semi-infinite clouds of radioactive noble gases
}

\author{
T.J. Stocki, M.-C. Lo, K. Bock, L.A. Beaton, S.D.R. Tisi, A. Tran, \\ T. Sullivan and R.K. Ungar \\ Radiation Protection Bureau, Health Canada, 775 Brookfield Rd, AL6302D1, \\ ON, K1A 1C1, Ottawa, Canada
}

\begin{abstract}
Health Canada maintains detector networks across Canada. One of these networks consists of $\mathrm{NaI}(\mathrm{Tl})$ detectors that measure air KERMA [1]. Located beside the $\mathrm{NaI}(\mathrm{Tl})$ detector in Ottawa is a radioxenon analyzer [2] that measures the activity concentration of ${ }^{131 \mathrm{~m}, 133 \mathrm{~m}, 133,135} \mathrm{Xe}$ directly. The ICRUaccepted KERMA to activity concentration conversion factor for ${ }^{133} \mathrm{Xe}$, for a semi-infinite cloud measured $1 \mathrm{~m}$ off the ground, is $9.68 \mathrm{pGy} / \mathrm{hr}$ per Bq $/ \mathrm{m}^{3}$ [3]. However, on various dates, the two detectors in Ottawa reported a conversion value of $2.6 \pm 0.2 \mathrm{pGy} / \mathrm{hr}$ per Bq $/ \mathrm{m}^{3}$; we have resolved this discrepancy [4] and have expanded on the study of other isotopes by focusing on the $\mathrm{NaI}(\mathrm{Tl})$ detector. Greater accuracy in the conversion value between the air KERMA and activity concentration will assist meteorological modellers in verifying their models [1]. Two Monte Carlo methods were used in this investigation. The first is the analogue geometry where the detector is immersed in a semi-infinite radioactive source. A second method is to apply a reciprocal transform of the analogue geometry. This expedited the calculation of larger clouds. By using these two methods together, we have calculated new values for KERMA rate to activity concentration for 4 of isotopes of noble gases, namely ${ }^{131 \mathrm{~m}} \mathrm{Xe},{ }^{133 \mathrm{~m}} \mathrm{Xe},{ }^{85} \mathrm{Kr},{ }^{85 \mathrm{~m}} \mathrm{Kr},{ }^{135} \mathrm{Xe}$.
\end{abstract}

\section{INTRODUCTION}

Health Canada's Radiation Protection Bureau (RPB) performs environmental and occupational radiation protection. RPB's responsibilities include nuclear verification, incident monitoring, and an active role as a member of the Comprehensive nuclear-Test-Ban Treaty (CTBT). To facilitate these roles, Health Canada maintains radiation detector networks across Canada, one of which consists of $\mathrm{NaI}(\mathrm{Tl})$ detectors [1] that measure the pulse height of gamma rays from radioactive noble gases and then converts these spectra into measured values for air KERMA rate. The operation and calibration of these detectors have been described by Grasty [5, 6]. Beside the $\mathrm{NaI}(\mathrm{Tl})$ detector in Ottawa is a radioxenon analyzer system known as the Système de Prélèvement d'air Automatique en Ligne avec l'Analyse des radioXénons (SPALAX) [2, 7]. The SPALAX measures the activity concentration of four isotopes of radioxenon $(131 \mathrm{~m}, 133 \mathrm{~m}, 133,135 \mathrm{Xe})$ as one of the four technologies (radionuclide monitoring, seismic, hydroacoustic, and infrasound) for compliance verification of the CTBT [6]. The International Commission on Radiological Units (ICRU) [4] accepted KERMA rate to activity concentration conversion factor, for a semi-infinite cloud measured $1 \mathrm{~m}$ off the ground, for ${ }^{133} \mathrm{Xe}$ is $9.68 \mathrm{pGy} / \mathrm{h}$ per Bq$/ \mathrm{m}^{3}$, which was determined by Jacob [3, 9]. However, after a weighted average over many observations, two detectors (SPALAX and $\mathrm{NaI}(\mathrm{Tl})$ ) at RPB reported a conversion value of $2.6 \pm 0.2 \mathrm{pGy} / \mathrm{h} \mathrm{per} \mathrm{Bq} / \mathrm{m}^{3}$. This apparent discrepancy has been resolved [4] and our techniques have been used to simulate other interesting radioactive noble gases $\left({ }^{131} \mathrm{Xe},{ }^{133 \mathrm{~m}} \mathrm{Xe},{ }^{85} \mathrm{Kr},{ }^{85 \mathrm{~m}} \mathrm{Kr},{ }^{135} \mathrm{Xe}\right)$. Greater accuracy in the air KERMA rate to activity concentration conversion value will assist meteorological modellers in verifying their atmospheric transport models [1]. In the event of an emergency, Environment Canada and other meteorological modelers will be able to model the movement of a radioactive cloud from the air KERMA value measured by Health Canada's $\mathrm{NaI}(\mathrm{Tl})$ network. From this meteorological model, a more accurate radiological dose assessment towards the public may be developed. 


\section{MONTE CARLO METHODS}

\subsection{The Russian doll method}

In this investigation two methods used the Monte Carlo software Electron Gamma Shower National Research Council (EGSnrc) [10]. The user routine DOSRZ was used to simulate the cylindrical geometry [11]. This first method is an analogue "brute force" method where a detector is immersed in a semi-infinite cloud radioactive source. In this method variance reduction techniques such as bremsstrahlung splitting or Russian roulette were not used, with the exception of photon interaction forcing. Rayleigh scattering also is not considered as it was found to have a negligible effect on the results. The geometry for these brute force simulations is best described as a "Russian Doll" where smaller dolls are encased in larger dolls. This is done by simulating a detector immersed in an isotropic source of radioactivity in the shape of a cylinder with the same height and radius. The subsequent simulation has the geometry of a larger cylinder inside of which contains a hollow cylinder with the same dimensions as the previous simulation. Since the sensitive volume or scoring region is always the same $7.62 \mathrm{~cm} \times 7.62 \mathrm{~cm}$ diameter cylindrical volume, the mass is constant and by use of the principle of superposition, these simulations may be added together; this is similar to putting all the dolls into each other without any gaps in between. The total KERMA is then the summation of the KERMA of all of the individual simulations. The scoring region is a $7.62 \mathrm{~cm} \times 7.62 \mathrm{~cm}$ diameter volume of air, which is $1 \mathrm{~m}$ off the ground. The disadvantage of the "brute force" method is that the computational time is very long, and increases with cloud size.

\subsection{The reciprocal transform method}

As a substantial improvement upon the Russian Doll method in terms of computational time, the second Monte Carlo method used was a reciprocal transformation [12] on the entire Russian Doll geometry. This transformation makes a condensed elongated source surrounded by a ring detector as shown in Figure 1. The reciprocal transform method was proven to be an acceptable calculation of the total KERMA by comparing the results obtained from it to the Russian Doll method. The greatest advantage of the reciprocal method is that it decreases the computational time significantly. Hence the reciprocal transform method may be used to calculate the total KERMA at much greater distances than the brute force method.
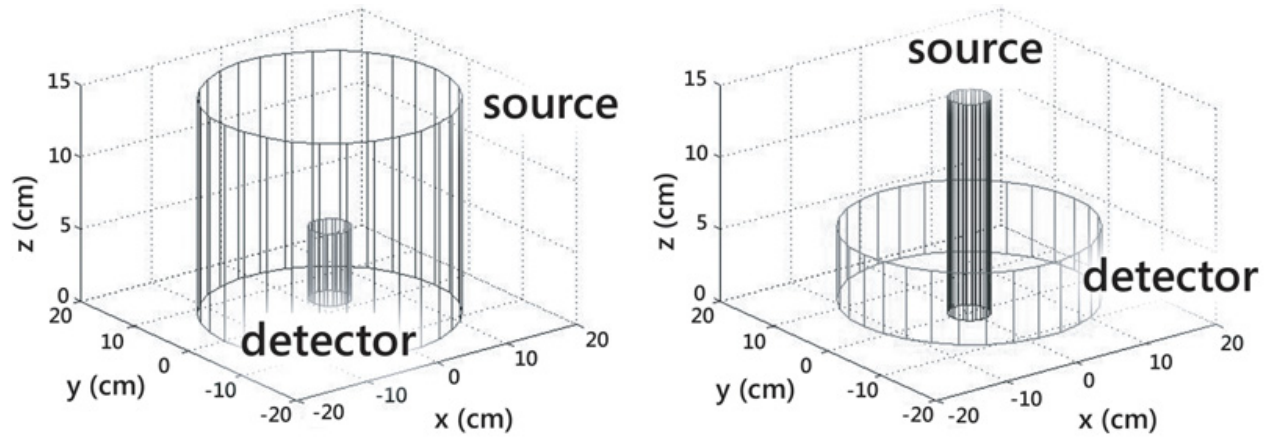

Figure 1. The original geometry of the brute force method (left) and the transformed geometry for the reciprocal transform method (right) with the detector and source.

The reciprocal transform can be described by the following transformation of the source and detector volumes:

$$
\begin{aligned}
\mathrm{V}_{\mathrm{S}}\left(\mathrm{x}_{\mathrm{S}}, \mathrm{y}_{\mathrm{S}}, \mathrm{z}_{\mathrm{S}}\right) & \rightarrow \mathrm{V}_{\mathrm{S}}\left(\mathrm{x}_{\mathrm{D}}, \mathrm{y}_{\mathrm{D}}, \mathrm{z}_{\mathrm{S}}\right) \\
\mathrm{V}_{\mathrm{D}}\left(\mathrm{x}_{\mathrm{D}}, \mathrm{y}_{\mathrm{D}}, \mathrm{z}_{\mathrm{D}}\right) & \rightarrow \mathrm{V}_{\mathrm{D}}\left(\mathrm{x}_{\mathrm{S}}, \mathrm{y}_{\mathrm{S}}, \mathrm{z}_{\mathrm{D}}\right)
\end{aligned}
$$


where the subscripts denote detector and source. There are three restrictions on using this transform [12]. The first is that the detector and source geometry can be expressed as a function of $\mathrm{x}$ and $\mathrm{y}$ over a range $z$. Next the strength of the source only depends on $z$. Thirdly, the transport kernel has the same symmetry as the above transformation.

\subsection{Tests of the methodology}

Because the goal was to try to understand the discrepancy for ${ }^{133} \mathrm{Xe}$, a number of very thorough tests were done on the methodology of the simulation. These tests were done on both methods. Simulations were run on a cloud with the size of $12 \mathrm{~m}$ ( $12 \mathrm{~m}$ radius by $12 \mathrm{~m}$ above the sensitive volume) using the Russian doll method. The luxury levels (the degree of randomness) on the random number generator were varied to see if the default setting was reasonable. It was found that the results of this test were consistent with the default setting. A second test was with a cloud with a size of $12 \mathrm{~m}$ which was broken into a $6 \mathrm{~m}$ cloud surrounded by another cloud, in such a manner to construct a $12 \mathrm{~m}$ cloud. The results of these separate simulations were summed and found to be consistent with the $12 \mathrm{~m}$ simulation. This confirmed the "Russian Doll" approach worked. To ensure that all of these simulations incorporated the ground/air interface effect, a $12 \mathrm{~m}$ "Russian Doll" simulation was run with $1 \mathrm{~m}$ of soil underneath. The results of this test were consistent with the non-soil geometry within $1 \sigma$ (one standard deviation).

Also test simulations were run on a large reciprocal transform method, namely a cloud which was $1 \mathrm{~km}$ in size. The first test was to see the effect of backscatter, so the $1 \mathrm{~km}$ simulation was surrounded by a $6 \mathrm{~km}$ source free volume. The results of this simulation were $2 \%$ different than the simulation that was not surrounded, but these results were well within $1 \sigma$.

Rayleigh scattering was also considered with the two methods and it was found that Rayleigh scattering agreed with the results without it, to within $1 \sigma$. Tests were also done with Atomic relaxations turned off (atomic relaxations were used in our calculations), for a $12 \mathrm{~m}$ cloud size, using the Russian Doll method. The results of this test were within $1 \sigma$. Finally the effect of turning off electron impact ionization was tested (it was on during our runs) and it was found that this also had a negligible effect.

\section{RESULTS}

To verify the reciprocal transform results, the brute force method was used up to 0.7 mean free paths of the most intense photon for each radioisotope. It was found in previous work with ${ }^{133} \mathrm{Xe}$ that the ratio of reciprocal to brute force results as a function of one over cloud size tended to level off at 0.7 mean free paths. So, for each isotope a graph of that function was made to ensure that it was flat, as in Figure 2. These results were fitted to a linear function. Then a statistical t-test was performed to determine if these graphs had a slope. The results of this statistical test are shown in Table 1. Then at a cloud size of $1 \mathrm{~km}$, the reciprocal transform geometry was simulated for each isotope and that result was placed in the second column of Table 2. These results can be considered as semi-infinite. By fitting the graphs to a line, the intercept of the graph was used as the correction factor in the third column of Table 2. Multiplying those two columns together, the results of our work are displayed in the $4^{\text {th }}$ column, where the error due to the correction is listed separately. This correction is applied to account for the slight difference between the "brute force" and reciprocal calculations. A more in-depth article on this work will be published.

For all of these calculations in this work, the energies and emission probabilities were taken from $\mathrm{NuDat}$ [13], except for the intensity of $233.2 \mathrm{keV} \gamma$-ray of ${ }^{133 \mathrm{~m}} \mathrm{Xe}$ where we used the updated value of Siiskonen and Toivonen [14]. Only photons with energies greater than $29 \mathrm{keV}$ and with emission probabilities greater than $0.3 \%$ were considered. 


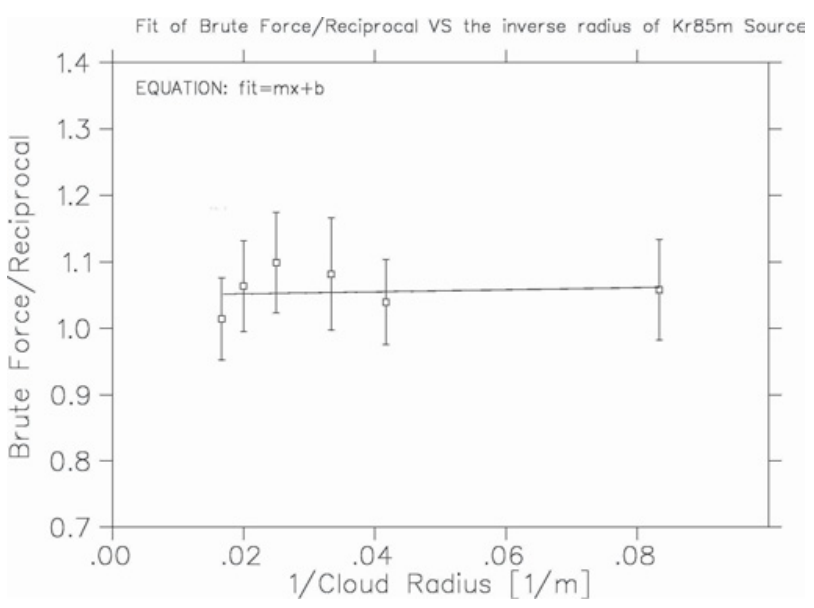

Figure 2. The graph of the ratio of the two methods as a function of one over the cloud size for ${ }^{85 \mathrm{~m}} \mathrm{Kr}$. The error bars are $1 \sigma$ (standard deviation).

Table 1. Table of isotopes and the results for the t-test. If p-value was greater than 0.05 , then the null hypothesis did not have enough evidence to be rejected, so the graph did not have a slope.

\begin{tabular}{|l|c|c|}
\hline Isotope & p-Value & Slope/No Slope \\
\hline${ }^{131 \mathrm{~m}} \mathrm{Xe}$ & 0.089 & No Slope \\
\hline${ }^{133 \mathrm{~m}} \mathrm{Xe}$ & 0.201 & No Slope \\
\hline${ }^{85} \mathrm{Kr}$ & 0.284 & No Slope \\
\hline${ }^{85 \mathrm{~m}} \mathrm{Kr}$ & 0.815 & No Slope \\
\hline
\end{tabular}

Table 2. Table of the results under study in comparison to ICRU 53, before and after the correction factor was applied to these results under study. The errors on the Result after correction are the statistical error $(1 \sigma)$ followed by the systematic error.

\begin{tabular}{|l|c|c|c|c|c|c|}
\hline & $\begin{array}{c}\text { Transform result } \\
\text { GGy/h per Bq/m }\end{array}$ & $\begin{array}{c}\text { Correction } \\
\text { Factor }\end{array}$ & $\begin{array}{c}\text { Result after correction } \\
\text { pGy/h per Bq/m }\end{array}$ & $\begin{array}{c}\text { ICRU [6] } \\
\text { pGy/h per } \\
\text { Bq/m }\end{array}$ & $\begin{array}{c}\text { \% diff } \\
\text { (transform } \\
\text { vs. ICRU) }\end{array}$ & $\#$ \\
\hline${ }^{131 \mathrm{~m}} \mathrm{Xe}$ & $4.05 \pm 0.19$ & $1.00 \pm 0.02$ & $4.05 \pm 0.19 \pm 0.07$ & - & - & - \\
\hline${ }^{133 \mathrm{~m}} \mathrm{Xe}$ & $6.85 \pm 0.32$ & $0.98 \pm 0.05$ & $6.71 \pm 0.32 \pm 0.34$ & - & - & - \\
\hline${ }^{135} \mathrm{Xe}$ & $40.5 \pm 1.7$ & On going & On going & 55.10 & 36 & 4 \\
\hline${ }^{85} \mathrm{Kr}$ & $0.405 \pm 0.011$ & $0.95 \pm 0.03$ & $0.380 \pm 0.011 \pm 0.012$ & 0.630 & 56 & 20 \\
\hline${ }^{85 \mathrm{~m}} \mathrm{Kr}$ & $24.21 \pm 0.91$ & $1.05 \pm 0.03$ & $25.4 \pm 0.9 \pm 0.7$ & 33.4 & 38 & 10 \\
\hline
\end{tabular}

The air KERMA rate to activity concentration factor was calculated for 4 radioisotopes. These results are shown in Table 2. These new results tend to be at least about $40 \%$ less than the ICRU value. This is currently under investigation by making the EGSnrc code mimic the Monte Carlo code YURI, which was used for the ICRU results. YURI has the feature to change the density of air as a function of height. The simulations presented here have been run in this fashion for one isotope and it was found that this did not explain the discrepancy. An effect that has been investigated is the finite size of our sensitive volume. Again this effect did not resolve the discrepancy. Another difference between YURI and our code is that YURI does not take into account electron slowing down effects. It is planned to have EGSnrc mimic this effect. It will also be worth investigating the differences between the new geometry presented 
here and YURI's. YURI used gamma rays which were detected by horizontal infinite detectors. In this work, the geometry of a semi-infinite cloud is represented by a large cylindrical cloud surrounding a cylindrical sensitive area.

\section{CONCLUSION}

In conclusion, a new set of values for air KERMA rate to activity concentration conversion factors have been calculated. The values in this study differ from the ICRU accepted values and the reason for this is still under study. However in this study a more realistic geometry is used, exact photon energies were used instead of extrapolations/interpolations, and only one variance reduction technique was used.

\section{References}

[1] Stocki T.J., Armad P., Heinrich Ph., Ungar R.K., D’Amours R., Korpach E.P., Bellivier A., Taffary T., Malo A., Bean M., Hoffman I. and Jean M., Measurement and Modeling of Radioxenon Plumes in the Ottawa Valley. J. Environ. Radioact. In press. (2008).

[2] Stocki, T.J., Blanchard X., D'Amours R., Ungar R.K., Fontaine, J.P., Sohier, M., Bean M., Taffary T., Racine J., Tracy B.L., Brachet G., Jean M. and Meyerhoff D., J. Environ. Radioact. 80 (2005) 305-326.

[3] ICRU International Commission on Radiation Units and Measures Report 53 (1994).

[4] Stocki T.J., Beaton L.A., Tran A., Bock K. and Ungar R.K. Nucl. Instr. Meth. A580 (2007) 683-686.

[5] Grasty R.T., Walters B.R.B., Hovgaard J. and LaMarre J.R. Radiat. Protect. Dosim. 94 (2001) 309-316.

[6] Grasty R.T., Hovgaard J. and LaMarre J. Radiat. Protect. Dosim. 95 (2001) 249-256

[7] Fontaine J.P., Pointurier F., Blanchard X. and Taffary T.J. Environ. Radioact. J 72 (2004) $129-135$.

[8] Sullivan J. D., Phys. Today 51, March (1998) 24-29.

[9] Jacob P., Rosenbaum H., Petoussi N. and Zankl M. Calculation of Organ Doses from Environmental Gamma Rays Using Human Phantoms and Monte Carlo Methods. Part II: Radionuclides Distributed in the Air or Deposited on the Ground. GSF Bericht 12/90. GSF-Forschungszentrum für Umwelt und Gesundheit, Oberschleibheim, Germany, ISSN:0721 (1990).

[10] Kawrakow, I. and Rogers, D.W.O., NRCC Report PIR-701/702, National Research Council of Canada (2003).

[11] Rogers, D.W.O., Kawrakow, I., Seuntjens, J.P., Walters, B.R.B. and Mainegra-Hing, E. NRC User Codes for EGSnrc. NRCC Report PIRS-702. National Research Council of Canada (2003).

[12] Zähringer M. and Sempau J., Calibration Factors for Dose Rate Probes in Environmental Monitoring Networks Obtained from Monte-Carlo-Simulations. Fachbereich Strahlenhygiene, Institut fur Atmospharische Radioaktivitat, Report Number BfS-IAR-2/97, p. 32 (1997).

[13] NUDAT website National Nuclear Data Center, information extracted from the NuDat database, http://www.nndc.bnl.gov/nudat2

[14] Siiskonen T. and Toivonen H., Radiat. Phys. Chem. 69 (2004) 23-24. 
